\title{
Gambaran Tingkat Kepuasan Pasien terhadap Pelayanan FNAB di Laboratorium Patologi Anatomi RSUD Abdul Wahab Sjahranie Samarinda Tahun 2018
}

\author{
The Level of Patient Satisfaction on Fnab Services in Anatomical Pathology \\ Laboratory of Abdul Wahab Sjahranie Samarinda Hospital 2018
}

\author{
Simanjuntak Mayro ${ }^{1}$, Eko Nugroho ${ }^{2}$, Oswald L Simatupang ${ }^{3}$ \\ 1) Program Studi Pendidikan Dokter Fakultas Kedokteran Universitas Mulawarman, Jl. Kerayan, Kampus Gn. Kelua \\ Telp.(0541) 748581,748449 Fax.748449 Samarinda 75119 \\ 2) Bagian Patologi Anatomi Fakultas Kedokteran Universitas Mulawarman, Jl. Kerayan, Kampus Gn. Kelua Telp.(0541) \\ 748581,748449 Fax.748449 Samarinda 75119 \\ 3) Bagian Ilmu Kesehatan Masyarakat Fakultas Kedokteran Universitas Mulawarman, Jl. Kerayan, Kampus Gn. Kelua \\ Telp.(0541) 748581,748449 Fax.748449 Samarinda 75119 \\ Korespondensi: mayrosimanjuntak1005@gmail.com
}

Submitted: 5 November 2018, Revised: 13 Desember 2018, Accepted: 26 Desember 2018

http://doi.org/10.22435/jpppk.v2i3.1075

\begin{abstract}
Abstrak
Kepuasan pasien adalah suatu tingkat perasaan pasien yang timbul akibat dari kinerja layanan kesehatan yang diperoleh setelah pasien membandingkan dengan apa yang diharapkannya, sehingga kepuasan pasien bergantung pada kualitas pelayanan yang diterimanya. Untuk menilai kualitas pelayanan terdapat 5 dimensi yang dapat diukur, yaitu keandalan (reliability), daya tanggap (responsiveness), jaminan (assurance), empati (empathy), dan keberwujudan (tangible). Makin baik kualitas pelayanan yang diberikan, maka akan semakin tinggi tingkat kepuasan pasien. Tujuannya untuk mengetahui tingkat kepuasan pasien terhadap pelayanan di laboratorium patologi anatomi RSUD Abdul Wahab Sjahranie Samarinda. Penelitian deskriptif dilakukan dengan teknik purposive sampling pada pasien yang datang ke Laboratorium Patologi Anatomi RSUD Abdul Wahab Sjahranie, Samarinda, yang memenuhi kriteria. Data yang peroleh berasal dari data primer dengan menggunakan kuesioner yang dikerjakan secara terbimbing. Terdapat kesenjangan (gap) harapan sebesar $-0,6$ untuk dimensi keandalan, -0,2 untuk dimensi daya tanggap, $-0,2$ untuk dimensi jaminan, $-0,1$ dimensi empati, dan $-0,9$ untuk dimensi keberwujudan. Tingkat kepuasan pasien adalah $96 \%$ responden puas dan $4 \%$ responden tidak puas.
\end{abstract}

Kata kunci: kepuasan pasien, pelayanan kesehatan, keandalan, daya tanggap, jaminan

\begin{abstract}
Patient satisfaction is a level of patient's feelings rising from the performance of health services that are obtained after the patient compares it with what he expected, so that patient satisfaction depends on the quality of service received. To assess service quality there are 5 dimensions that can be measured, namely reliability, responsiveness, assurance, empathy, and tangible. The better quality of service provided, the higher the level of patient satisfaction. To determine the level of patient satisfaction with services in the anatomical pathology laboratory of the Abdul Wahab Sjahranie Hospital, Samarinda. Descriptive study was conducted by purposive sampling technique carried out on 50 patients who came to the Anatomical Pathology Laboratory of Abdul Wahab Sjahranie Hospital, in Samarinda that met the criteria. The data obtained comes from primary data using a questionnaire that is done in a guided manner. There was an expectation gap of -0.6 for reliability dimensions, -0.2 for responsiveness dimensions, -0,2 for assurance dimensions, -0.1 empathy dimensions
\end{abstract}


and $-0,9$ for tangible dimensions. The level of patient satisfaction was $96 \%$ of respondents were satisfied and $4 \%$ of respondents were dissatisfied.

Keywords: patient satisfaction, health services, reliability, responsiveness, assurance

\section{Pendahuluan}

Pelayanan kesehatan merupakan upaya yang diselenggarakan sendiri atau secara bersamasama dalam suatu organisasi untuk memelihara dan meningkatkan kesehatan, mencegah dan menyembuhkan penyakit, serta memulihkan kesehatan, perorangan, keluarga, kelompok, ataupun masyarakat. ${ }^{1}$

Pelayanan kesehatan memiliki tujuan utama untuk meningkatkan kesehatan dan mencegah penyakit dengan masyarakat sebagai sasaran utamanya. Ruang lingkup pelayanan kesehatan masyarakat cukup banyak, sehingga peran pemerintah dalam pelayanan kesehatan sangatlah besar. ${ }^{2}$ Setiap warga negara berhak mendapat pelayanan kesehatan dan negara bertanggung jawab atas penyediaan fasilitas pelayanan kesehatan dan fasilitas pelayanan umum yang layak.

Kualitas pelayanan rumah sakit (RS) mempunyai dua komponen yang dinilai, yaitu pemenuhan terhadap standar mutu yang telah ditetapkan dan pemenuhan akan kepuasan pelanggan. RS harus memberikan pelayanan yang berfokus pada kepuasan pelanggan. Perbaikan kualitas pelayanan kesehatan dapat dimulai dengan mengevaluasi setiap unsur yang berperan dalam membentuk kepuasan pasien. ${ }^{3}$

Salah satu unsur atau unit penunjang di RS yang patut dievaluasi adalah laboratorium patologi anatomi. Pelayanan laboratorium termasuk dalam sistem pelayanan kesehatan yang tidak bisa dipisahkan dari upaya pelayanan kesehatan secara keseluruhan. Laboratorium patologi anatomi merupakan salah satu sarana kesehatan yang diharapkan mampu memberikan pelayanan terbaik terhadap kebutuhan individu dan masyarakat dalam rangka mewujudkan Indonesia Sehat yang berperan sebagai pendukung dalam penegakan suatu diagnosis penyakit dalam upaya peningkatan kesehatan yang optimal. ${ }^{4}$

Laboratorium patologi anatomi adalah laboratorium kesehatan yang melaksanakan pelayanan pemeriksaan spesimen klinik untuk mendapatkan informasi tentang kesehatan perorangan, terutama untuk menunjang upaya penegakan diagnosis penyakit, penyembuhan penyakit, dan pemulihan kesehatan, melaksanakan pembuatan preparat histopatologi, pulasan khusus sederhana, pembuatan preparat sitologi, dan pembuatan preparat dengan teknik potong beku. Laboratorium patologi anatomi hanya dapat melakukan pemeriksaan laboratorium atas permintaan tertulis dari dokter spesialis patologi anatomi. $^{5}$

Aspek patologi anatomi melihat kelainan struktur sel dan jaringan yang terlihat pada pemeriksaan makroskopis dan mikroskopis jaringan yang diambil dari pasien. Laboratorium patologi anatomi di RS meliputi subdivisi, seperti patologi pembedahan, sitologi, hematopatologi, dan patologi otopsi. ${ }^{6}$

Berdasarkan hasil pra-penelitian teknik pemeriksaan yang paling sering dilakukan di Laboratorium Patologi Anatomi RS Umum Daerah (RSUD) Abdul Wahab Sjahranie adalah Fine Needle Aspiration Biopsy (FNAB). FNAB adalah teknik yang digunakan untuk membantu diagnosis berbagai penyakit tumor, baik sebagai upaya diagnosis preoperatif maupun konfirmatif, dengan cara mengambil jaringan tersangka tumor menggunakan jarum ukuran $23-22 \mathrm{G}$ atau yang lebih $\operatorname{kecil}(24,25,27 \mathrm{G})^{7}$

Perbaikan pelayanan berdasarkan penilaian kualitas oleh pasien dan penilaian kepuasan pasien telah dilakukan di banyak RS di dunia. Oleh karena itu harapan dan kenyataan yang dialami pasien akan pelayanan kesehatan perlu digali dan dilakukan perubahan agar sesuai dengan harapan pasien memperoleh pelayanan terbaik yang memuaskan. ${ }^{8}$ Salah satu indikator keberhasilan pelayanan kesehatan adalah kepuasan pasien. Tingkat kepuasan pelanggan terhadap pelayanan merupakan faktor yang penting dalam mengembangkan suatu sistem penyediaan pelayanan yang tanggap terhadap kebutuhan pelanggan, meminimalkan biaya dan waktu, serta memaksimalkan dampak pelayanan 
terhadap populasi sasaran. ${ }^{9}$

Tujuan penelitian adalah untuk mengetahui gambaran tingkat kepuasan pasien terhadap pelayanan kesehatan di Laboratorium Patologi Anatomi RSUD Abdul Wahab Sjahranie, Samarinda, yang adalah salah satu dari dua laboratorium patologi anatomi yang ada di Kalimantan Timur. Selain itu laboratorium patologi anatomi di Kalimantan Timur tersebut merupakan laboratorium rujukan utama pelayanan patologi anatomi kesehatan di wilayah Kalimantan Timur. Dengan adanya penelitian ini dapat diketahui apakah Laboratorium Patologi Anatomi RSUD Abdul Wahab Sjahranie, Samarinda, sudah memberikan pelayanan yang baik dan memberikan kepuasan kepada pasien. Hasil penelitian diharapkan akan berguna untuk meningkatkan kualitas pelayanan di Laboratorium Patologi Anatomi RSUD Abdul Wahab Sjahranie, Samarinda, yang merupakan bagian penting dari kesuksesan tujuan pelayanan kesehatan.

\section{Metode}

Penelitian ini merupakan penelitian deskriptif berupa survei kualitatif untuk menggambarkan tingkat kepuasan pasien terhadap pelayanan kesehatan di Laboratorium Patologi Anatomi RSUD Abdul Wahab Sjahranie, Samarinda, yang dilakukan selama 1 bulan. Pengambilan sampel pada penelitian ini dilakukan dengan teknik purposive sampling, yaitu suatu metode pengambilan sampel yang dilakukan secara sengaja oleh peneliti dan memenuhi kriteria inklusi dan eksklusi yang telah ditetapkan sebelumnya agar peneliti mendapatkan sampel yang paling sesuai. Kriteria inklusi pada penelitian ini adalah usia pasien minimal 12 tahun, pasien bersedia mengikuti penelitian dan pasien yang telah mendapatkan pelayanan kesahatan pemeriksaan FNAB di ruang pemeriksaaan laboratorium patologi anatomi yang dapat menjawab pertanyaan dengan baik, sedangkan kriteria ekslusinya adalah pasien tidak bersedia terlibat dalam proses penelitian.

Perhitungan besar sampel untuk menjawab masalah penelitian menggunakan rumus slovin dan besar sampel yang akan digunakan pada penelitian ini adalah 50 sampel. Penelitian ini dilakukan di Laboratorium Patalogi Anatomi RSUD Abdul Wahab Sjahranie, Samarinda, karena sudah memenuhi dimensi-dimensi yang diteliti dalam metode
Service Quality (SERVQUAL), yaitu manajemen, sumber daya, sarana, dan prasarana. Penelitian ini menggunakan data primer dengan instrumen yang digunakan berupa kuesioner SERVQUAL dengan beberapa modifikasi untuk mempermudah pemahaman dari pasien dan beberapa modifikasi sesuai dengan keadaan laboratorium. Kuesioner terdiri dari 20 pernyataan. Pernyataan-pernyataan tersebut akan mewakili 5 dimensi kualitas pelayanan berupa keandalan (reliability), ketanggapan (responsiveness), jaminan (assurance), perhatian (emphaty), dan keberwujudan (tangiable) menjadi parameter yang akan diukur pada penelitian ini.

\section{Hasil}

Penelitian ini dilakukan di Laboratorium Patologi Anatomi RSUD Abdul Wahab Sjahranie, Samarinda, selama satu bulan. Selama periode penelitian terdapat 50 pasien yang akan di-FNAB dan memenuhi kriteria inklusi dan eksklusi di Laboratorium Patologi Anatomi RSUD Abdul Wahab Sjahranie, Samarinda.

Berdasarkan Tabel 1 terlihat bahwa responden yang mendapatkan pelayanan kesehatan di Laboratorium Patologi Anatomi RSUD Abdul Wahab Sjahranie selama periode penelitian lebih banyak perempuan, yaitu sebanyak 29 orang (58\%), lebih banyak pada kelompok lansia awal (usia 46-55 tahun), yaitu sebanyak 11 orang (22\%), terbanyak berprofesi sebagai pegawai swasta (26\%), dan yang memiliki tingkat pendidikan menengah sebanyak 21 orang $(42 \%)$.

Tabel 2 menunjukkan bahwa dari 50 pasien yang mengikuti penelitian didapatkan 48 orang merasa puas dengan keseluruhan dimensi pelayanan yang ada di Laboratorium Patologi Anatomi RSUD Abdul Wahab Sjahranie, Samarinda, dan 2 orang merasa tidak puas.

Tabel 3 menunjukan harapan dari pernyataanpernyataan yang mewakili dimensi keandalan berkisar antara 4,4 sampai 4,6, kenyataan berkisar antara 3,7 sampai 4,2 memiliki kesenjangan (gap) berkisar antara $-0,4$ hingga $-0,9$. Didapatkan nilai rata-rata harapan adalah 4,5 , sedangkan rata-rata kenyataan adalah 3,9 dan rata-rata kesenjangan adalah $-0,6$.

Tabel 4 menunjukan harapan dari pernyataanpernyataan yang mewakili dimensi ketanggapan 
Tabel 1. Karakteristik Demografis

\begin{tabular}{lcc}
\hline \multicolumn{1}{c}{ Karakteristik } & Jumlah & Persentase \\
\hline Jenis Kelamin & & \\
Laki-laki & 21 & $42 \%$ \\
Perempuan & 29 & $58 \%$ \\
Total & 50 & $100 \%$ \\
Rentang Usia (WHO) & & \\
12-16 tahun & 3 & $6 \%$ \\
17-25 tahun & 8 & $16 \%$ \\
26-35 tahun & 9 & $18 \%$ \\
36-45 tahun & 10 & $20 \%$ \\
46-55 tahun & 11 & $22 \%$ \\
56-65 tahun & 9 & $18 \%$ \\
Total & 50 & $100 \%$ \\
Jenis Pekerjaan & & \\
Pegawai negeri sipil & 10 & $20 \%$ \\
Pegawai swasta & 13 & $26 \%$ \\
Wiraswasta & 7 & $14 \%$ \\
Ibu Rumah Tangga & 9 & $18 \%$ \\
Pelajar/mahasiswa & 8 & $16 \%$ \\
Tidak Bekerja & 3 & $6 \%$ \\
Total & 50 & $100 \%$ \\
Tingkat Pendidikan & & \\
Rendah & 17 & $34 \%$ \\
Menengah & 21 & $42 \%$ \\
Tinggi & 12 & $24 \%$ \\
Total & 50 & $100 \%$ \\
\hline
\end{tabular}

Tabel 2. Nilai Tingkat Kepuasan

\begin{tabular}{|c|c|c|}
\hline $\begin{array}{c}\text { Tingkat Kepuasan } \\
\text { Pasien }\end{array}$ & Jumlah & Persentase \\
\hline Pasien Puas & 48 orang & $96 \%$ \\
\hline Pasien Tidak Puas & 2 orang & $4 \%$ \\
\hline Total & 50 orang & $100 \%$ \\
\hline
\end{tabular}

berkisar antara 4,1 sampai 4,4, kenyataan berkisar antara 4 sampai 4,2 memiliki kesenjangan berkisar antara $-0,4$ hingga 0,1 . Didapatkan nilai rata-rata harapan adalah 4,3, sedangkan rata-rata kenyataan adalah 4,1, dan rata-rata kesenjangan adalah -0,2.

Tabel 5 menunjukan harapan dari pernyataanpernyataan yang mewakili dimensi jaminan berkisar antara 4 sampai 4,4, kenyataan berkisar antara 3,4 sampai 4,3 memiliki kesenjangan berkisar antara $-0,6$ hingga 0,2 . Didapatkan nilai rata-rata harapan adalah 4,2, sedangkan rata-rata kenyataan adalah 4 dan rata-rata kesenjangan adalah -0,2.

Tabel 6 menunjukan harapan dari pernyataanpernyataan yang mewakili dimensi empati berkisar antara 4,2 sampai 4,4, kenyataan berkisar antara 4,3 sampai 4,5 memiliki kesenjangan berkisar -0,1 sampai 0,3 . Didapatkan nilai rata-rata harapan adalah 4,3, sedangkan rata-rata kenyataan adalah 4,4 dan rata-rata kesenjangan adalah 0,1 .

Tabel 7 menunjukkan harapan dari pernyataanpernyataan yang mewakili dimensi keberwujudan berkisar antara 4 sampai 4,6, kenyataan berkisar antara 1,5 sampai 3,9 memiliki kesenjangan berkisar antara $-0,2$ hingga $-0,1$. Didapatkan nilai rata-rata harapan adalah 4,2, sedangkan rata-rata kenyataan adalah 3,3 dan rata-rata kesenjangan adalah $-0,9$.

\section{Pembahasan}

Nilai rata-rata persepsi dari seluruh dimensi kepuasan yang diukur sebesar 3,8 yang termasuk kategori puas. Hal ini hampir serupa dengan penelitian yang dilakukan Mardiana tahun 2012 tentang kualitas pelayanan di Laboratorium Klinik RSUD Sukoharjo yang berada pada kategori puas, dengan nilai persepsi $4,4 .^{10}$

Berdasarkan Tabel 3, diajukan 3 pernyataan untuk menilai dimensi keandalan. Pernyataan pertama adalah 'loket administrasi dan petugas beroperasi tepat sesuai jadwal yang sudah ditentukan'. Beberapa pasien merasa belum puas dengan ketepatan jadwal operasi loket administrasi yang mengakibatkan pasien menunggu. Nilai pada pernyataan 'loket administrasi dan petugas beroperasi tepat sesuai jadwal yang sudah ditentukan' juga disebabkan oleh keluhan beberapa pasien yang mendapati petugas loket beristirahat sebelum jadual istirahat yang sudah ditentukan sehingga menyebabkan pasien menunggu. Selain itu, penyebab lain nilai negatif pada pernyataan 'loket administrasi dan petugas beroperasi tepat sesuai jadual yang sudah ditentukan' adalah keluhan beberapa pasien yang mendapati memanjangnya waktu istirahat loket administrasi sehingga membuat pasien menunggu lebih lama untuk loket administrasi kembali beroperasi. Ketidakpuasan 
Tabel 3. Nilai Dimensi Keandalan

\begin{tabular}{clccc}
\hline No & \multicolumn{1}{c}{ Pernyataan } & Harapan & Kenyataan & Kesenjangan \\
\hline 1 & $\begin{array}{l}\text { Loket administrasi dan petugas beroperasi tepat sesuai } \\
\text { jadwal yang sudah ditentukan }\end{array}$ & 4,6 & 3,7 & $-0,9$ \\
2 & $\begin{array}{l}\text { Waktu tunggu pelayanan mulai dari pendaftaran hingga } \\
\text { penerimaan hasil pemeriksaan }\end{array}$ & 4,4 & 3,7 & $-0,7$ \\
3 & $\begin{array}{l}\text { Dokter dan petugas memberikan pelayanan tepat sesuai } \\
\text { jadwal pelayanan yang dijadwalkan } \\
\text { RATA-RATA }\end{array}$ & 4,6 & 4,2 & $-0,4$ \\
$\quad 4,5$ & 3,9 & $-0,6$ \\
\hline
\end{tabular}

Tabel 4. Nilai Dimensi Ketanggapan

\begin{tabular}{clccc}
\hline No & \multicolumn{1}{c}{ Pernyataan } & Harapan & Kenyataan & Kesenjangan \\
\hline 1 & $\begin{array}{l}\text { Petugas membantu proses administrasi dan alur } \\
\text { pelayanan dengan baik dan tanggap }\end{array}$ & 4,4 & 4 & $-0,4$ \\
2 & $\begin{array}{l}\text { Dokter melayani dengan sabar, tidak terburu-buru, dan } \\
\text { tanggap }\end{array}$ & 4,1 & 4,2 & 0,1 \\
& RATA-RATA & 4,3 & 4,1 & $-0,2$ \\
\hline
\end{tabular}

Tabel 5. Nilai Dimensi Jaminan

\begin{tabular}{clccc}
\hline No & \multicolumn{1}{c}{ Pernyataan } & Harapan & Kenyataan & Kesenjangan \\
\hline 1 & Dokter dan petugas tampil rapi dan profesional & 4,1 & 4,3 & 0,2 \\
2 & Ruang pemeriksaan tertutup, aman, dan nyaman & 4,4 & 4,3 & $-0,1$ \\
3 & $\begin{array}{l}\text { Dokter mampu menjawab pertanyaan dari pasien yang } \\
\text { belum merasa jelas }\end{array}$ & 4,3 & 4,2 & $-0,1$ \\
\multirow{2}{*}{4} & Lingkungan laboratorium aman, bersih, dan nyaman & 4 & 3,4 & $-0,6$ \\
\multicolumn{2}{r}{ RATA-RATA } & 4,2 & 4 & $-0,2$ \\
\hline
\end{tabular}

Tabel 6. Nilai Dimensi Empati

\begin{tabular}{clccc}
\hline No & \multicolumn{1}{c}{ Pernyataan } & Harapan & Kenyataan & Kesenjangan \\
\hline 1 & $\begin{array}{l}\text { Dokter dan petugas bersikap ramah dan peduli } \\
\text { terhadap pasien }\end{array}$ & 4,4 & 4,3 & $-0,1$ \\
2 & $\begin{array}{l}\text { Dokter berusaha membuat pasien merasa nyaman dan } \\
\text { rileks saat pemeriksaan } \\
\text { RATA-RATA }\end{array}$ & 4,2 & 4,5 & 0,3 \\
$\quad 4,3$ & 4,4 & 0,1 \\
\hline
\end{tabular}

yang diperoleh pada tahap awal pelayanan menimbulkan persepsi berupa kualitas pelayanan yang buruk untuk tahap pelayanan berikutnya, sehingga pasien tidak puas dengan pelayanan secara keseluruhan, yang membuat penyelenggara kesehatan harus memiliki persepsi yang sama dengan pelanggan agar diperoleh hasil yang melebihi atau paling tidak sama dengan harapan pelanggan. ${ }^{11}$

Pernyataan kedua adalah 'waktu tunggu pelayanan mulai dari pendaftaran hingga penerimaan hasil pemeriksaan'. Sebagian kecil pasien yang menganggap waktu tunggu pelayanan, mulai dari pendaftaran hingga penerimaan hasil, terlalu lama. Namun, sebagian pasien memaklumi waktu tunggu tersebut dan menganggap bahwa memang dibutuhkan waktu begitu lama untuk memperoleh hasil pemeriksaan yang tepat. Waktu tunggu umumnya dirasakan sebagai masalah, 
Tabel 7. Nilai Dimensi Keberwujudan

\begin{tabular}{clccc}
\hline No & \multicolumn{1}{c}{ Pernyataan } & Harapan & Kenyataan & Kesenjangan \\
\hline 1 & $\begin{array}{l}\text { Kondisi fisik gedung atau bangunan laboratorium baik } \\
\text { dan terpelihara }\end{array}$ & 4,3 & 3,6 & $-0,7$ \\
2 & $\begin{array}{l}\text { Mudah menemukan lokasi dan mencapai gedung } \\
\text { laboratorium patologi anatomi }\end{array}$ & 4 & 3,9 & $-0,1$ \\
3 & $\begin{array}{l}\text { Ruang tunggu laboratorium bersih, rapi, dan nyaman } \\
4\end{array}$ & 4,5 & 3,5 & -1 \\
$\quad \begin{array}{l}\text { Ruang tunggu memiliki sarana hiburan untuk mengisi } \\
\text { waktu menunggu }\end{array}$ & 4,6 & 3,6 & -1 \\
5 & $\begin{array}{l}\text { Tersedia majalah, pamflet, dan media informasi tentang } \\
\text { patologi anatomi dan dasar-dasar penyakit serta cara }\end{array}$ & 4 & 3,9 & $-0,1$ \\
$\quad \begin{array}{l}\text { pencegahannya } \\
6\end{array}$ & Toilet bersih, aman, dan nyaman digunakan & 4,1 & 1,5 & $-2,6$ \\
$\quad$ RATA-RATA & 4,2 & 3,3 & $-0,9$ \\
\hline
\end{tabular}

terutama ketika pasien banyak menumpuk di ruang tunggu, sedangkan jumlah staf yang memberikan pelayanan terbatas. $^{12}$

Pernyataan ketiga adalah 'dokter memberikan pelayanan tepat sesuai jadwal pelayanan yang sudah ditentukan'. Sebagian besar pasien merasa puas bahwa dokter yang bertugas memberikan pelayanan sudah melaksanakan kewajibannya sesuai dengan jadwal yang sudah ditentukan. ${ }^{13}$

Setelah melihat hasil yang sudah didapatkan dari dimensi keandalan, maka diperlukan perbaikan di ketiga pernyataan secara menyeluruh. Para dokter dan petugas diharapkan dapat meningkatkan ketepatan jadwal saat melaksanakan pelayanan, sehingga dapat menjawab keluhan dari pasien dan meningkatkan kualitas pelayanan.

Dimensi ketanggapan terdapat dua pernyataan yang mewakili dimensi ini, yaitu petugas membantu proses admistrasi dan alur pelayanan dengan baik dan tanggap serta dokter melayani dengan baik dan sabar, tidak terburu-buru, dan tanggap. Pada pernyataan 'petugas membantu proses administrasi dan alur pelayanan dengan baik dan tanggap', beberapa pasien masih merasa kurang mendapat bantuan yang diharapkan saat mendapatkan kendala pada proses administrasi dan alur pelayanan. Kondisi seseorang yang sakit cenderung menjadi lebih sensitif dan mudah tersinggung, karena tubuh sedang dalam keadaan tidak seimbang. Hal ini juga akan mempengaruhi kejiwaan dan emosi pasien, sehingga pasien sangat mengharapkan pelayanan yang cepat, tepat, dan penuh perhatian. ${ }^{14}$
Pernyataan 'dokter melayani dengan sabar, tidak terburu-buru, dan tanggap', sebagian besar pasien merasa puas dengan pelayanan pemeriksaan yang menganggap dokter sudah melakukan pelayanan secara tanggap, sabar, dan tidak terburuburu.

Penelitian yang menyangkut kepuasan pasien di RSUP H. Adam Malik menunjukkan aspek kepuasan daya tanggap lebih berpengaruh dibandingkan dengan kepuasan lainnya. Dimensi ketanggapan adalah kemampuan petugas pelayanan kesehatan membantu pasien dan memberikan pelayanan dengan tanggap terhadap kebutuhan pasien, cepat memperhatikan dan mengatasi kebutuhan pasien setiap diminta atau menawarkan bantuan sebelum diminta. ${ }^{14}$ Jadi, tinggal diperlukan sedikit perbaikan terhadap dimensi ketanggapan agar dapat meningkatkan kualitas pelayanan.

Dimensi jaminan, terdapat 4 pernyataan yang mewakili dimensi ini, yaitu dokter dan petugas tampil rapi dan profesional; ruang pemeriksaan tertutup, aman, dan nyaman; dokter mau menjawab pertanyaan dari pasien yang merasa belum jelas; serta lingkungan laboratorium aman, bersih, dan nyaman. Pada pernyataan 'dokter dan petugas tampil rapi dan profesional', sebagian besar pasien menilai bahwa dokter dan petugas sudah tampil rapi dan profesional. Pada pernyataan kedua, 'ruang pemeriksaan tertutup, aman, dan nyaman'. Pernyataan ini sudah mencapai nilai positif, hanya ada beberapa pasien yang mengeluh tentang suhu ruangan yang terlalu dingin untuk 
mereka. Kemudian pada pernyataan 'dokter mau menjawab pertanyaan dari pasien yang merasa belum jelas', beberapa pasien belum merasa puas dengan jawaban yang mereka dapatkan dari dokter. Hal ini bisa disebabkan oleh kesalahan pemahaman komunikasi antara dokter dan pasien yang bertanya. Pada pernyataan 'lingkungan laboratorium aman, bersih dan nyaman, pasien merasa lingkungan laboratorium' belum memenuhi harapan keamanan, kebersihan, dan kenyamanan dari pasien. Jaminan lingkungan merupakan terjaminnya tingkat keamanan lingkungan unit penyelenggara sehingga pasien merasa tenang untuk memperoleh pelayanan yang dapat mewujudkan kepercayaan pelayanan. ${ }^{15}$

Dimensi empati, diwakili dengan menggunakan 2 pernyataan, yaitu pernyataan 'dokter dan petugas bersikap ramah, sopan, dan peduli dengan pasien' serta pernyataan 'dokter berusaha membuat pasien merasa nyaman dan rileks saat pemeriksaan'. Pada pernyataan 'dokter dan petugas bersikap ramah, sopan, dan peduli dengan pasien', sebagian besar pasien menganggap dokter dan petugas sudah bersikap ramah, sopan, dan peduli terhadap pasien. Kemudian, pada pernyataan 'dokter berusaha membuat pasien nyaman dan rileks pada saat pemeriksaan', sebagian besar pasien sudah terpenuhi harapannya dalam hal sikap dokter yang berusaha membuat pasien merasa nyaman dan rileks saat pemeriksaan. Secara garis besar pelayanan yang unggul memiliki 4 unsur, yaitu kecepatan, ketepatan, keramahan, dan kenyamanan yang terintegrasi menjadi satu kesatuan sehingga pelayanan akan menjadi tidak sempurrna bila ada salah satu hal tersebut terabaikan. ${ }^{16}$

Dimensi empati memiliki kesenjangan paling kecil dari penilaian yang sudah didapatkan di penelitian ini, sehingga hanya diperlukan sedikit peningkatan lagi untuk dapat memenuhi harapan pasien, yang akan meningkatkan tingkat kepuasan dari pasien.

Dimensi keberwujudan diwakili 6 pernyataan. Pernyataan pertama adalah 'kondisi fisik gedung atau bangunan laboratorium baik dan terpelihara'. Pada pernyataan ini beberapa pasien menganggap kondisi fisik gedung atau bangunan laboratorium masih baik namun suasana terkesan agak gelap.

Pernyataan kedua adalah 'mudah menemukan lokasidanmencapailaboratoriumpatologianatomi’.
Pada pernyataan ini pasien menganggap masih kurang penunjuk arah yang ada untuk mempermudah mereka menemukan dan mencapai laboratorium patologi anatomi. Pernyataan ketiga adalah 'ruang tunggu laboratorium patologi anatomi rapi, bersih, dan nyaman'. Pada pernyataan ini beberapa pasien berpendapat bahwa untuk menambah kenyamanan ruang tunggu bisa dengan mengganti kursi yang ada di ruang tunggu menggunakan kursi yang lebih empuk serta nyaman digunakan untuk duduk sambil menunggu. Pernyataan keempat yang digunakan untuk mewakili adalah 'ruang tunggu memiliki sarana hiburan untuk mengisi waktu selama menunggu'. Pada pernyataan ini beberapa pasien menganggap sudah cukup disediakan televisi sebagai sarana hiburan. Namun, sebagian besar pasien masih merasakan kurangnya sarana hiburan di ruang tunggu, sebagian besar pasien berharap untuk ditambahnya sarana hiburan, terutama jaringan internet nirkabel atau wi-fi. Hal ini tidak terlepas dari semakin meningkatnya kebutuhan internet manusia pada masa kini. Menurut buku "Pedoman Teknis Sarana dan Prasarana Rumah Sakit Tahun 2010", di instalasi laboratorium hendaknya disediakan sarana umum pada ruang tunggu, seperti televisi dan telepon umum jika RS mampu. ${ }^{17}$

Pernyataan kelima adalah 'tersedia majalah, pamflet, atau media informasi tentang patologi anatomi dan dasar-dasar penyakit serta cara pencegahannya'. Beberapa pasien menganggap masih kurangnya media tersebut tersedia, padahal mereka ingin membaca dan menambah wawasan dasar tentang penyakit-penyakit yang diperiksa di laboratorium anatomi, terutama cara-cara pencegahannya. Hal ini juga dapat dimanfaatkan sebagai pengisi waktu selama mereka menunggu. Masih menurut buku "Pedoman Teknis Sarana dan Prasarana Rumah Sakit Tahun 2010”, hendaknya di instalasi laboratorium disediakan perpustakaan atau ruang baca pada ruang tunggu dan pencahayaan sesuai standar, yang akan meningkatkan kenyamanan pasien dan mempengaruhi kepuasan pasien. Pernyataan terakhir yang digunakan untuk mewakili dimensi tangibles adalah 'toilet bersih, aman, dan nyaman digunakan'. Pada pernyataan ini pasien mengatakan rusaknya toilet yang dimiliki laboratorium patologi anatomi menyebabkan pasien harus mencari toilet lain yang letaknya cukup jauh 
dari laboratorium patologi anatomi. Kepuasan pasien dapat ditingkatkan dengan disediakannya toilet yang memenuhi syarat-syarat seperti tidak berbau, bersih, harus selalu tersedia air bersih yang cukup untuk digunakan, lantai tidak licin, dan pintu toilet dapat ditutup dengan mudah.

Hasil penilaian dimensi keberwujudan sejalan dengan penelitian tentang kualitas pelayanan di instalasi radiologi RSUD Panembahan Senopati, Bantul, yang mendapatkan keberwujudan sebagai dimensi dengan kesenjangan paling besar, yaitu senilai $-0,9$ dan keseluruhan dimensi dengan skor negatif. ${ }^{18}$ Hal ini juga didukung oleh penelitian tentang kualitas pelayanan RSUD Wonogiri yang mendapatkan keberwujudan sebagai dimensi dengan kesenjangan paling besar, yaitu $-0,4$ dan keseluruhan dimensi memiliki kesenjangan negatif senilai $-0,165 .{ }^{19}$

Berdasarkan hasil penelitian, terdapat beberapa faktor yang dapat mempengaruhi tingkat kepuasan pasien terhadap pelayanan FNAB di Laboratorium RSUD Abdul Wahab Sjahranie, Samarinda, yaitu:

a. Pasien sedang dalam kondisi kurang sehat sehingga kondisi fisik dan emosi pasien lebih sensitif. Hal ini dapat berpengaruh pada penilaian dari pasien.

b. Pengisian kuesioner secara terpimpin sedikit banyak akan mempengaruhi keputusan penelitian dari pasien.

c. Peneliti tidak membandingkan penilaian pasien dengan penilaian keluarga/pendamping pasien yang kondisinya lebih sehat dan normal.

\section{Kesimpulan}

Berdasarkan hasil penelitian terhadap 50 responden, terdapat 48 responden (96\%) yang mengaku puas dan "hanya" terdapat 2 responden (4\%) yang mengaku tidak puas pada pada pelayanan kesehatan di Laboratorium Patologi Anatomi RSUD Abdul Wahab Sjahranie, Samarinda berdasarkan dimensi keandalan, ketanggapan, jaminan, empati, dan keberwujudan.

\section{Saran}

Berdasarkan keseluruhan hasil diketahui terdapat kesenjangan yang bernilai negatif di kelima dimensi, maka harus dilakukan usaha perbaikan pelayanan pada keseluruhan dimensi, terutama pada dimensi yang memiliki kesenjangan paling besar (yakni dimensi keberwujudan) dan dapat dilakukan penelitian selanjutnya secara rutin dan berkala karena penilaian dapat berubah sejalan dengan dimensi tingkat kepuasan pasien yang dinamis dari waktu ke waktu.

\section{Daftar Rujukan}

1. AL-Abri R, Al-Balushi A. Patients Satisfaction Survey As A Tool Toward Quality Improvement. Oman Med J. Januari 2014; 29(1). 3-7.

2. Azwar A. Menjaga Mutu pelayanan Kesehatan Aplikasi Prinsip Lingkaran Pemecahan Masalah. Jakarta: Pustaka Sinar Harapan; 2007.

3. Febriani VA. Analisis Pengaruh Kualitas Pelayanan terhadap Kepuasan Konsumen (Studi pada Pasien Poliklinik Rawat Jalan Rumah Sakit Dr. Cipto Mangunkusumo). Skripsi, Semarang: Fakultas Ekonomi dan Bisnis Universitas Diponegoro; 2012.

4. Depkes RI. UU RI No.23 Tahun 1992 tentang Kesehatan. Depkes RI. Jakarta; 1992.

5. Permenkes.. Laboratorium Klinik. Jakarta: 2010. 411.

6. Chandrasoma P, Taylor CR. Ringkasan Patologi Anatomi (Concise Pathologi). Edisi 2. Jakarta: EGC; 2006. 574, 576.

7. Koss LG. Koss' Diagnostic Cytology And Its Histopathologic Bases. 5th Edition. Philadelphia: Lippincott Williams \& Wilkins; 2006. 1149-1172.

8. Priatna E. Penilaian Pasien tentang Kualitas Pelayanan Obstetri Dan Ginekologi di Rumah Sakit Umum Pusat Nasional Dokter Cipto Mangunkusumo Jakarta dan Faktor-Faktor Yang Berhubungan. Jakarta; 2009.

9. Rosni, F. Kepuasan Pelanggan Internal. Yogyakarta: Bagian/Instalasi Patologi Klinik FK UGM; 2009.

10. Mardiana, Budiadi, NA, Kristanto, Y. Pengaruh Kualitas Pelayanan Laboratorium terhadap Tingkat Kepuasan Pasien Rawat Jalan pada Laboratorium Klinik RSUD Sukoharjo. Surakarta: Fakultas Ilmu Kesehatan Universitas Setia Budi; 2012.

11. Fajar, Laksana. Manajemen Pemasaran Pendekatan Praktis. Cetakan ke-1. Yogyakarta: 
Grahallmu; 2008.

12. Ayubi, D. 2009. Penilaian Kualitas Pelayanan Puskesmas dengan Model Donabedian: Studi Kasus Puskesmas di Kota Depok. Jurnal Kesehatan Masyarakat Nasional.2009. 24

13. Irawan, H. 10 Prinsip Kepuasan Pelanggan. Jakarta: Elex media komputindo; 2002.

14. Sulistiyowati, B. Analisa Dimensi Service Quality (SERVQUAL) terhadap Asuhan Keperawatan di Ruang Perawatan Umum I dan UU di RS Sentra Medika. Tesis. Jakarta : Universitas Indonesia; 2010.

15. Rahmawati EF, Pudjirahardjo WJ. Analisis Kepuasan Pasien terhadap Kualitas Pelayanan dengan Teori Donabedian di Instalasi Laboratorium. Jurnal Administrasi Kesehatan Indonesia. Januari - Maret 2014; Volume 2 Nomor 1.

16. Tjiptono, F. Strategi Pemasaran. Edisi Kedua.
Cetakan Keenam. Yogyakarta: Penerbit Andi; 2002.

17. Dabri RA, Paranoan DB, Paselle, E. Analisis Hubungan Kualitas Pelayanan dengan Tingkat Kepuasan Pengunjung Pasien Kelas III Rumah Sakit Jiwa Daerah Atma Husada Mahakam Samarinda Tahun 2013. eJournal Administrative Reform. 2014; 2 (2): 1304-1315.

18. Suharyanta D, A'yunin Q. Analisis Tingkat Kualitas Pelayanan Jasa Menggunakan Metode Service Quality (SERVQUAL) Fuzzy di Instalasi Radiologi Rumah Sakit Umum Daerah (RSUD) Panembahan Senopati Bantul Tahun 2012. KesMas: Jurnal Fakultas Kesehatan Masyarakat. 2013; Vol 7, No 1.

19. Aisyati A, Rochman T, Rahmadi H. Analisa Kualitas Pelayanan Rumah Sakit Umum Daerah (RSUD) Wonogiri Menggunakan Metode Fuzzy-SERVQUAL. Gema Teknik. 2007; Vol 10, No 2. 